\title{
Bentonite electrical conductivity: a model based on series-parallel transport
}

\author{
Ana T. Lima $\cdot$ J. P. Gustav Loch $\cdot$ Pieter J. Kleingeld
}

Received: 10 September 2009/Accepted: 21 December 2009/Published online: 30 January 2010

(C) The Author(s) 2010. This article is published with open access at Springerlink.com

\begin{abstract}
Bentonite has significant applications nowadays, among them as landfill liners, in concrete industry as a repairing material, and as drilling mud in oil well construction. The application of an electric field to such perimeters is under wide discussion, and subject of many studies. However, to understand the behaviour of such an expansive and plastic material under the influence of an electric field, the perception of its electrical properties is essential. This work serves to compare existing data of such electrical behaviour with new laboratorial results. Electrical conductivity is a pertinent parameter since it indicates how much a material is prone to conduct electricity. In the current study, total conductivity of a compacted porous medium was established to be dependent upon density of the bentonite plug. Therefore, surface conductivity was addressed and a series-parallel transport model used to quantify/predict the total conductivity of the system.
\end{abstract}

Keywords Bentonite - Series-parallel transport .

Electrical conductivity $\cdot$ Surface conductivity

\section{Introduction}

Bentonite is a type of clay consisting predominantly of smectite minerals, usually montmorillonite and beidellite, described by Coban and Ece [1] and Sposito [2] and was first described by Knight [3] as a highly plastic and highly

A. T. Lima $(\bowtie)$ · J. P. G. Loch · P. J. Kleingeld Department of Earth Sciences, Geochemistry, Faculty of Geosciences, Utrecht University, PO Box 80.021, 3508 TA Utrecht, The Netherlands

e-mail: lima.at@gmail.com; a.lima@geo.uu.nl weathering resistance material. This particular type is highly swelling in the presence of moisture, and its large double-layer (DL) is convenient for the retention of cations, toxins, etc. Because of this particular feature, bentonite is widely used for different purposes. The uses are as wide as clarification of wine and beer [4], as beauty products, confinement of hazardous, nuclear and radioactive wastes e.g. [5, 6], as geosynthetic clay liner, and some bentonite cross applications with concrete for retention of contaminants in waste solidification/stabilization techniques were also proposed e.g. [7].

When debating the properties of a compacted bentonite liner or plug, the differences are significant from the material in suspension. Several studies have been carried out to understand the behaviour of particular species in compacted bentonite plug, where double-layers (DL) are overlapping since they are so thick. Kozaki et al. [8] and Bourg et al. $[9,10]$ are some examples of studies of diffusivity of ions in compacted sodium bentonites. Electrical conductivity of colloids and clay-rich porous materials is a pertinent parameter when studying electrokinetic applications.

Electrokinetic (EK) barriers are an example where an electric field is applied to clay liners in order to retain contaminants in them $[11,12]$. Also, EK has previously been proposed for monitoring synthetic geoclay liners [13] and in 2004 a patent has been created for the EK treatment of landfill clay liners (US Patent 6736568-Electrokinetic geosynthetic structure).

EK is a technique which has been widely used, from the stabilization of quick clays [14] to the decontamination of polluted soil e.g. [15]. EK has been tested for the remediation of contaminated matrixes with organic, inorganic and radionuclide's species [15] and is particularly suited in the treatment of fine-grained, highly organic or argillaceous soils, with high water content [16]. The conduction of 
electric current through a medium is performed by the ions present in them, no matter the ionic form or the ion in question [17].

To understand how electric current is transported throughout a compacted porous medium, a series of measurements have been carried out on a compacted bentonite plug, with density as a variable. A conductivity transport model was used, based on the series-parallel transport model introduced by Mitchell [4], to understand the experimental data.

\section{Series-parallel transport}

When electric current crosses a homogeneous porous medium, its conduction throughout the medium is more complex than in a uniform non-porous solid material, such as copper or gold. The migration of water, ions and other charged solid particles towards the electrodes are the main phenomena which take place when electrokinetics is applied to a moistened porous medium. Charged negative colloidal particles and anions in the media, are moved towards the anode by electrophoresis while positive ions and water are being dragged to the cathode.

Hence, the content and distribution of ions throughout a porous membrane, as well as the size of the pores and water content, will strongly influence the passage of electric current.

In the following, the effect of these parameters on the electrical conductivity is summarized. The model of series-parallel transport is mentioned by Mitchell [4] and assumes that total electrical conductivity $\sigma_{T}$ of a porous medium is given by:

$\sigma_{T}=\frac{a \sigma_{W} \sigma_{S}}{(1-e) \sigma_{W}+e \sigma_{S}}+b \sigma_{S}+c \sigma_{W}$

where $\sigma_{W}$ is the electrical conductivity of the pore water or bulk solution, $\sigma_{T}$ is the electrical conductivity of the saturated soil, $\sigma_{S}$ is the surface electrical conductivity, $a, b, c$ and $e$ are geometric parameters that can be written as functions of porosity and degree of saturation.

The model integrates two types of transports which are parallel, where current is transported either by the bulk solution $\left(\sigma_{w}\right)$ or by the surface of the colloids $\left(\sigma_{s}\right): 2$ and 3, respectively, in Fig. 1. Series transport implies the alternate transport of current by the two parallel system: bulk solution and particles surface path, 1 in Fig. 1 and Eq. 1. This model assumes that electric double layers play a large role in conduction. Summarizing, current may be dragged not only in the three phases (water, solid, interface) separately, but crosses the interface between the different phases, creating a discontinuity in the electrical conductance/ resistance.

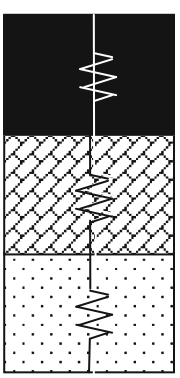

(1)

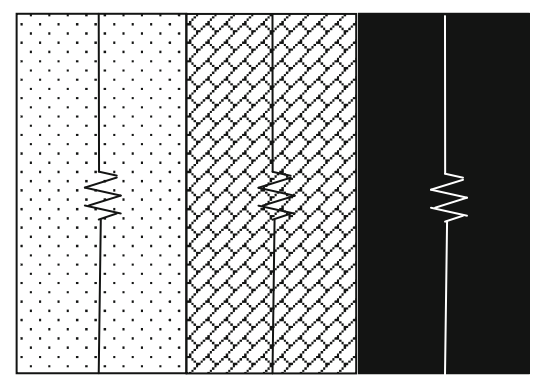

(2)
(3)
(4)
Fig. 1 Series (1) and parallel (2-4) transport represented graphically (adapted from [4]): 1 transport in series though bulk/surface and solid phases, 2 bulk solution, 3 surface interface, 4 solid

The introduction of a solid phase is mentioned here as an addition to Mitchell's model [4]: the conduction of electric current by the solid part, i.e. the clay minerals themselves (4 in Fig. 1). When considering a well compacted bentonite plug, where clay particles are so close that double layers overlap and there is not much free water in the pores, the clay minerals themselves may play a significant role in the transport of electric current. Table 1 summarizes the electrical conductivity and resistivity of some minerals, Si and alkali based. The conductivities of such minerals differ according to their composition. For instance, the $\mathrm{Al}$ based mineral bauxite presents a much higher conductivity than the Si based, e.g. quartz (Table 1). Bentonite composition is mainly $\mathrm{SiO}_{2}$, about $70 \%$, with smaller fraction of $\mathrm{Al}_{2} \mathrm{O}_{3}$, circa $15 \%$ [18, 19]. Solid conductivity of bentonite should approximate that of quartz.

Table 2 summarizes the total electrical conductivity of compacted bentonite from different studies. Significant variation is observed. These differences may be related to variations in the experimental conditions, such as porosity or density, moisture content or even the heterogeneity of bentonite. According to Velde and Meunier [21], bentonite, like most of the smectite types, is an inter layered clay type with mixed layered minerals, usually with non-exchangeable ions, suggesting that the behaviour of 2:1 minerals is variable and the material present is heterogeneous. Surface conductivity will play an important role in such a system and have a large influence if the density of the clay is increased by compaction. Since particles are closer together in a compacted system, and concentration of ions is higher close to the charged surfaces, it can be reasoned that compaction leads to higher conductivity. For this, surface conductivity should be quantified.

\subsection{Electrical conductivity and surface conductivity}

When an electric field is applied to a porous medium, a series of coupled flow phenomena occurs. Fluids, electric current, solutes and heat all take part in the physical and 
Table 1 Electrical resistivity and conductivity of different minerals [20]

\begin{tabular}{llll}
\hline Mineral & Formula & Resistivity $(\Omega \mathrm{m})$ & Conductivity $(\mathrm{S} / \mathrm{m})$ \\
\hline Calcite & $\mathrm{CaCO}_{3}$ & $2 \times 10^{12}$ & $5 \times 10^{-13}$ \\
Bauxite & $\mathrm{Al}_{2} \mathrm{O}_{3} \cdot n \mathrm{H}_{2} \mathrm{O}$ & $2 \times 10^{2}-6 \times 10^{3}$ & $5 \times 10^{-3}-1.7 \times 10^{-4}$ \\
Halite & $\mathrm{NaCl}$ & $30-10^{13}$ & $3.3 \times 10^{-2}-10^{-13}$ \\
Quartz & $\mathrm{SiO}_{2}$ & $4 \times 10^{10}-2 \times 10^{14}$ & $2.5 \times 10^{-11}-5 \times 10^{-15}$ \\
Sylvite & $\mathrm{KCl}$ & $10^{11}-10^{12}$ & $10^{-11}-10^{-12}$ \\
Feldspar porphyry & - & $4 \times 10^{3}$ (wet) & $2.5 \times 10^{-4}$ \\
\hline
\end{tabular}

Table 2 Conductivity of compacted bentonite in different studies

\begin{tabular}{ll}
\hline Bentonite in a confined volume & Electrical conductivity $(\mathrm{S} / \mathrm{m})$ \\
\hline The present study & $3.06 \times 10^{-4}-9.37 \times 10^{-6}$ \\
Heister et al. [22] & $0.0598-0.105$ \\
Heister [23] & $5.75 \times 10^{-5}$ \\
Lockhart and Stickland [24] & 0.0577 \\
Grundl and Michalski [25] & 0.0138 \\
Cherepy and Wildenschild [26] & 0.0320 \\
\hline
\end{tabular}

chemical behavior of a soil [4]. Each flow type is described in terms of analogous equations: Darcy's law for water flow; Fourier's law for heat flow; Ohm's law for electrical flow; and Fick's law for chemical flow. Electrical conductivity $\left(\sigma_{T}\right)$ in a soil-water system is ruled by Ohm's law and is inversely related to electrical resistance. It can be simply defined as

$\sigma_{T}=\frac{1}{R} \frac{L}{A}$

where $R$ is the resistance (ohm), $L$ the length of the sample (m) and $A$ the cross sectional area $\left(\mathrm{m}^{2}\right)$. The resistance is simply given by the quotient between the voltage drop across a medium/material (V) and $E$ the electric field (A).

Total electrical conductivity $\left(\sigma_{T}\right)$ is modeled in various ways. The Helmholtz-Smoluchowski theory for electroosmotic flow, for instance, assumes that the radius of the equivalent soil pore (approached by a capillary tube) is large compared with thickness of the double-layer surrounding the clay particles and that the mobile charge is concentrated near the wall, i.e., that the surface conductivity is negligible $[4,27]$. But in more recent models the double layer of clays has attracted more attention and surface conductivity has been taken into account. For a colloidal system, the total conductivity, $\sigma_{T}$, can be expressed as the sum of a bulk solution contribution and a surface contribution [28]. The following expression results from the assumption of a cylindrical capillary pore

$\sigma_{T}=\left(\sigma_{W}+2 \frac{\sigma_{S}}{a}\right)=\sigma_{W}(1+2 D u)$

where $\sigma_{W}$ is the bulk solution conductivity, $\sigma_{S}$ is the surface conductivity, $D u$ is the Dukhin number (dimensionless) and $a$ is the curvature radius of the pore. This equation is based on Ohm's law [28]. The Dukhin number, $D u$, relates the surface $\left(\sigma_{s}\right)$ and bulk water $\left(\sigma_{w}\right)$ conductivities by

$D u=\frac{\sigma_{S}}{\sigma_{W} a}$

Thus surface conductivity is accounted in the total conductivity. To calculate surface conductivity, Smoluchowski's theory is no longer considered valid. This means that the condition $\kappa a<1$ is then required, where $\kappa\left(\mathrm{m}^{-1}\right)$ is the inverse of the Debye length and it is represented by

$\kappa=\left\{\frac{\sum_{i=1}^{N} e^{2} z_{i}^{2} c_{i}}{\varepsilon_{r s} \varepsilon_{0} k T}\right\}^{1 / 2}$

where $e(\mathrm{C})$ is the elementary charge, $z$ is the valence of ions in a symmetrical electrolyte, $c$ is the electrolyte concentration (ions $\left.\mathrm{m}^{-3}\right), k$ is the Boltzmann constant $\left(\mathrm{J} \mathrm{K}^{-1}\right)$, $\varepsilon_{r s}$ is relative permittivity of the dispersion medium (dimensionless), $\varepsilon_{0}$ is electric permittivity of vacuum $\left(\mathrm{F} \mathrm{m}^{-1}\right.$ ) and $T(\mathrm{~K})$ is thermodynamic temperature [28].

Moreover, surface conductivity can be divided into a contribution of the diffuse double layer outside the plane of shear $\sigma_{s d}$, and a contribution of the stagnant layer $\sigma_{s i}$ :

$\sigma_{S}=\sigma_{S i}+\sigma_{S d}$

However, $\sigma_{S i}$ is considered not to contribute to the overall $\sigma_{S}$, since the charge in the stagnant layer is generally assumed to be immobile [28]. A model for surface conductivity $\left(\sigma_{S d}\right)$ in the mobile part of the diffuse double layer has been developed by Bikerman [29]:

$$
\begin{aligned}
\sigma_{S d}= & \frac{2 e^{2} N_{A} z^{2} c}{\kappa T k}\left[D_{+}\left(e^{-z e \zeta / 2 k T}-1\right)\left(1+\frac{3 m_{+}}{z^{2}}\right)\right. \\
& \left.+D_{-}\left(e^{z e \zeta / 2 k T}-1\right)\left(1+\frac{3 m_{-}}{z^{2}}\right)\right]
\end{aligned}
$$

where $D_{+}$and $\left(D_{-}\right)$are the diffusion coefficients of counterions $\left(\mathrm{m}^{2} \mathrm{~s}^{-1}\right), N_{A}$ is the Avogadro constant $\left(\mathrm{mol}^{-1}\right), \zeta(\mathrm{V})$ electrokinetic or zeta-potential and $m_{+}$ and $\left(m_{-}\right)$are the dimensionless mobilities of the cations and anions. $m$ is defined as: 
$m_{ \pm}=\frac{2}{3}\left(\frac{k T}{e}\right)^{2} \frac{\varepsilon_{r s} \varepsilon_{0}}{\eta D_{ \pm}}$

where $\eta$ is the dynamic viscosity ( $\mathrm{Pa} \mathrm{s}$ ). $m_{ \pm}$is a measure of the relative contribution of electroosmosis to the surface conductivity. For a symmetrical $z-z$ electrolyte and identical cation and anion diffusion, coefficients $m_{+}=$ $m_{-}=m$ [28]. Hence Du can be written as

$D u=\frac{2}{\kappa a}\left(1+\frac{3 m}{z^{2}}\right)+\left[\cosh \left(\frac{z e \zeta}{2 k T}\right)-1\right]$

Summarizing, the surface conductivity $\sigma_{S d}$ can be calculated through a series of experimentally determined parameters and predefined constants, and by Du, when the electrolyte is symmetric [28].

\section{Materials and methods}

Colclay A90TM (Geertruidenberg, The Netherlands) bentonite, a sodium montmorillonite with one-third of the exchange capacity occupied by calcium, was used. An amount of $10.0 \mathrm{~g}$ of bentonite was weighted and saturated with $0.01 \mathrm{M} \mathrm{NaCl}$ for 5 days under a hydraulic head of about $30 \mathrm{~cm}$. The cell where the bentonite was placed is presented in Fig. 2. After the saturation period, electric conductivity of the clay plug was determined at different densities. For this purpose, the clay plug was tightened to a dry density of about $1.5 \mathrm{~g} \mathrm{~cm}^{-3}$ and then slowly expanded while letting $0.01 \mathrm{M} \mathrm{NaCl}$ solution enter the clay, with intervals of approximately $1 \mathrm{~h}$, up to the limit of the cell, which corresponds to a density of 0.6. The density information is compiled in Table 5.

The cell of $5 \mathrm{~cm}$ diameter is made out of PVC. At the top and bottom of the cell, two caps are placed. These caps are topped by a porous stone of about $5 \mathrm{~mm}$ thickness and a gold electrode. The porous material of sintered silicon oxide is from ELE Intertest, Etten Leur, The Netherlands and has a porosity of about $50 \%$. The gold electrodes were glued to the porous stone, and connected to the outside current supplier by sintered silicon oxide wire. $0.01 \mathrm{M}$ $\mathrm{NaCl}$ solution was fed through the bottom cap, and saturated the bentonite.

A constant electric current was then applied along the clay membrane and electrical conductivity was determined by Ohms law (see Eq. 2). A direct current (DC) of $10 \mu \mathrm{A}$ was used, resulting in a current density of $0.005 \mathrm{~A} \mathrm{~m}^{-2}$. The voltage over the cell is monitored with an electrometer (Orion A520, $\mathrm{pH} / \mathrm{mV}$ meter). The effective current across the clay is supplied and quantified at the gold electrodes, as seen in Fig. 2. The conductivity is calculated as result of the applied current and measured voltage.

A Malvern Zetasizer Nano was used for determining the zeta potential of the bentonite. For these measurements, bentonite was added to subsequently distilled water, 0.1 and $0.01 \mathrm{M} \mathrm{NaCl}$ solutions in a $0.04 \%$ liquid-to-solid ratio. The resulting zeta potential measurement is estimated based on the presumption that the particles are spherical (Smoluchowski theory), with the Huckel approximation, which is a rough estimate.
Fig. 2 Laboratory cell designed for electroosmotic experiments and its schematic representation

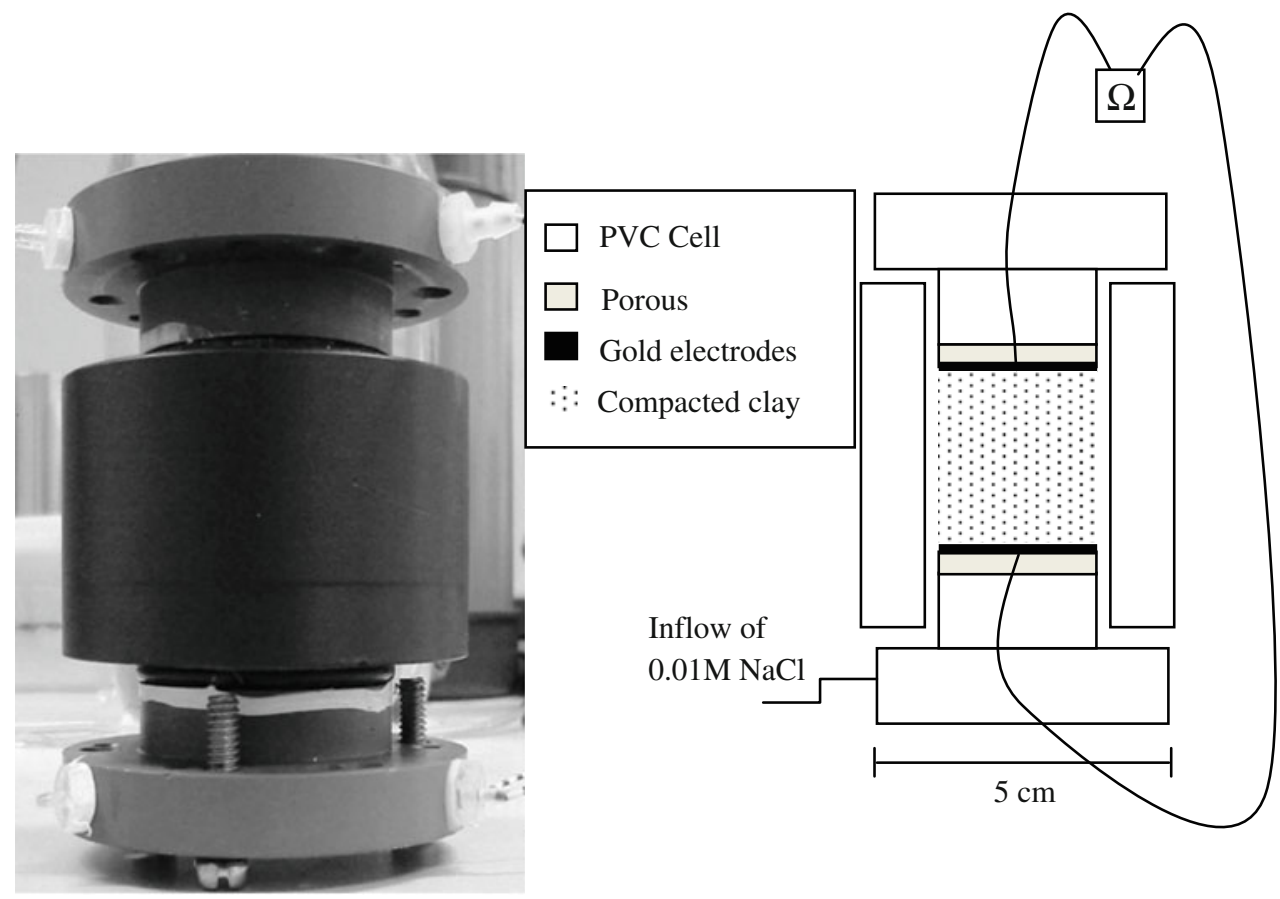




\section{Results and discussion}

The determination of total conductivity of bentonite at a given density was calculated through Ohm's law (Eq. 2), where current density and electric field strength were determined experimentally. Figure 3 presents total conductivity as a function of density or compaction of bentonite.

The experimental data imply an increase of bentonite's electrical conductivity with increasing density. Since the clay is compacted in a system where movement of particles is minimum, electrophoretic movement is considered negligible and hence not accountable. In such a compacted system, the thick double layers of bentonite are considered to be overlapping and the free (bulk) solution is minimal or absent. The ions in the double layers are then forming a positively charged network, creating (hypothetical) preferential paths for the electric current to pass.

The series-parallel transport model might explain such an increase of electrical conductivity, since it relates bulk and surface conductivities with parameters that are a function of porosity and degree of saturation [4].

To calculate surface conductivity through Eq. 7, the actual $\zeta$-potential of the bentonite in $0.01 \mathrm{M} \mathrm{NaCl}$ is needed. Table 3 presents the experimental values. According to Leroy and Revil [30], surface conductivity of smectite appears rather independent of salinity, on contrary to kaolinite. Here we observe a certain dependence, the $\zeta$-potential decreases with increasing concentration of salt of the pore solution. For the continuation of this study, zeta potential is considered $\zeta=-51.6 \mathrm{mV}$.

The original Bikerman equation for calculation of surface conductivity, Eq. 7, requires a series of parameters. These parameters are tabulated in Table 4. Most of them were taken from literature. Diffusion coefficients of $\mathrm{Na}$ [31] and $\mathrm{Cl}$ [8], in particular, were adopted from other studies where the system was similar to a compacted Na-bentonite. Based on Kozaki et al. [8], $\mathrm{Cl}^{-}$diffusivity decreases with increasing bentonite density. This can be

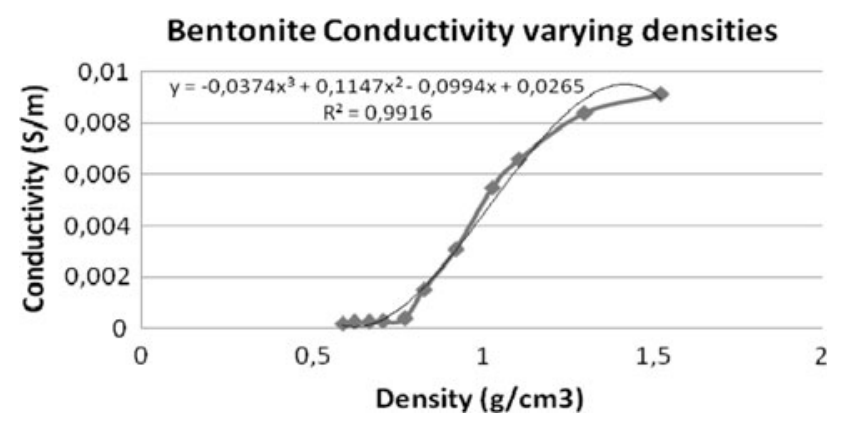

Fig. 3 Experimental values for total electrical conductivity of compacted bentonite at different densities
Table 3 Variation of bentonite's zeta potential with increasing salt concentration on bulk solution

\begin{tabular}{lll}
\hline Conditions & $\begin{array}{l}\text { Apparent mobility } \\
\left(\mathrm{cm}^{2} \mathrm{~V}^{-1} \mathrm{~s}^{-1}\right)\end{array}$ & $\begin{array}{l}\text { Zeta potential } \\
(\mathrm{mV})\end{array}$ \\
\hline $\begin{array}{l}\text { Bentonite in distilled } \\
\text { water }\end{array}$ & $-4.1 \times 10^{-4} \pm 0.05$ & $-78.5 \pm 10.2$ \\
$\begin{array}{l}\text { Bentonite in } 0.01 \mathrm{M} \\
\mathrm{NaCl}\end{array}$ & $-4.05 \times 10^{-4} \pm 0.32$ & $-52.8 \pm 4.55$ \\
$\begin{array}{l}\text { Bentonite in } 0.1 \mathrm{M} \\
\mathrm{NaCl}\end{array}$ & $-3.4 \times 10^{-4} \pm 0.28$ & $-43.6 \pm 3.59$ \\
\hline
\end{tabular}

explained by salt sieving due to anion exclusion from the diffuse double layers. This effect corroborates the assumption that at higher densities the network of ions at the surface of bentonite is in fact denser. Since the electrolyte was previously considered symmetrical, diffusivity of $\mathrm{Cl}$ was then used in the calculations.

Griffiths and Joshi [37] observed $10 \mathrm{~nm}$ pore radius and this was in agreement with previous literature. However, these authors assumed that most of the water present in a soil is not participating in double layer interactions [37]. While this might be valid for some clayey soils, it is not true for a pure bentonite as used in this study. It is believed that nearly all water existing in compacted bentonite clay is present as double layer water. Pore radius size was then adopted from [32], which is in conformity with e.g. [38].

After calculating surface conductivity at different densities, the model of Eq. 1 for total conductivity was fitted to the experimental curve of Fig. 2. For this, parameters $a, b$, $c$ and $e$ have to be addressed. Mitchell [4] suggests that the geometric parameters $a, b, c$ and $e$ can be written as functions of porosity and degree of saturation. However, Shainberg et al. [39] establish that Eq. 1 coefficients are as follows:

- $\quad a$ is the product of $b$ and $c$

- $b$ is the volume fraction taken in by surface space

- $c$ is the volume fraction taken in by water space

- $e \approx c$.

The surface space was calculated through the inverse of Debye length $(\kappa)$. If the double layers were not truncated because of close proximity of neighboring particles, the calculated surface volume, for the amount of studied bentonite $(10 \mathrm{~g})$, would largely exceed the cell volume. However, due to compaction, the double layers (which equals surface space) completely overlap and feel the whole pore space. This makes the fraction of free aqueous solution close to zero. Using directly the estimated parameters (Table 5) in Eq. 1 for predicting total conductivity implies the assumption of no tortuosity in the bentonite plug (see Fig. 1). However, the electrical flow path is admittedly tortuous. To correct this aspect, tortuosity was 
Table 4 Values needed for calculating equations $x$ and $y$

\begin{tabular}{|c|c|c|c|c|}
\hline Symbol & Description & Source & Value & Observations \\
\hline & Specific surface area & {$[22]$} & 611.00 & $\left(\mathrm{~m}^{2} / \mathrm{g}\right)$ \\
\hline$\kappa$ & Inverse of Debye length & Equation 5 & 1989733.3 & $\mathrm{~m}^{-1}$-Considering $\mathrm{Na}$ and $\mathrm{Cl}$ \\
\hline$a$ & Radius of pores & [32] & $4.00 \times 10^{-09}$ & $\mathrm{~m}$ \\
\hline$\kappa \cdot a$ & & Calculated & $7.96 \mathrm{E}-03$ & Inferior to 1: Smoluchowski's theory not valid \\
\hline$k$ & Boltzmann constant & & $1.38 \times 10^{-23}$ & $\mathrm{~J} \mathrm{~K}^{-1}$ \\
\hline$e$ & Elementary charge & & $1.60 \times 10^{-19}$ & $\mathrm{C}$ \\
\hline$z$ & Valence of ions & & 1 & Dimensionless \\
\hline$\sigma_{W}$ & Bulk solution conductivity & Experimental & $6.37 \times 10^{-4}$ & $\begin{array}{l}\mathrm{S} \mathrm{m}^{-1} \text {-Conductivity of } 0.01 \mathrm{M} \mathrm{NaCl} \\
\text { in the same setup (Fig. 2) }\end{array}$ \\
\hline$c$ & Electrolyte concentration & Experimental & $1.00 \times 10^{-5}$ & $\mathrm{~mol} \mathrm{~m}^{-3}$ \\
\hline $\mathrm{Na}$ & Avogadro constant & & $6.02 \times 10^{+23}$ & $\mathrm{~mol}^{-1}$ \\
\hline$\zeta$ & Electrokinetic (or zeta) potential & Experimental & -0.0528 & $\mathrm{~V}$ \\
\hline $\mathrm{T}$ & Temperature & Experimental & 283.15 & $\mathrm{~K}$ \\
\hline$\varepsilon_{r s}$ & Relative permittivity of water & {$[33]$} & 78.54 & \\
\hline$\varepsilon_{0}$ & Electric permittivity of vacuum & & $8.85 \times 10^{-12}$ & $\mathrm{~F} \mathrm{~m}^{-1}$ \\
\hline$\rho_{\text {bulk }}$ & Bulk density & {$[34,35]$} & 1.85 & $\mathrm{~g} \mathrm{~cm}^{-3}$-Used to calculate porosity \\
\hline$\rho_{\text {particle }}$ & Intrinsic density & {$[10]$} & 2.84 & $\begin{array}{l}\text { of the system, where } \phi \text { is the porosity: } \\
\phi=1-\frac{\rho_{\text {bulk }}}{\rho_{\text {bute }}}\end{array}$ \\
\hline$a$ & Equivalent radius of pores & {$[32]$} & $4.00 \times 10^{-09}$ & $\mathrm{~m}$ \\
\hline$D_{+}$ & $\begin{array}{l}\text { Diffusion coefficient sodium } \\
\text { in compacted bentonite }\end{array}$ & {$[31]$} & $1.7 \times 10^{-12}$ & $\mathrm{~m}^{2} \mathrm{~s}^{-1}$ \\
\hline$\eta$ & Dynamic viscosity & [36] & $1.01 \times 10^{-2}$ & Pa s-of water at $293 \mathrm{~K}$ \\
\hline
\end{tabular}

used as a fitting parameter [39]. It should be noted that soil tortuosity, $\tau$, is essentially unmeasurable [40], and the value of the bentonite tortuosity may be estimated from Archie's equation [41].

The parameters for fitting Eq. 1 model are presented in Table 5 and the resulting curve in Fig. 4.

The diffusivity of ions is used in the calculation of surface conductivity; the resulting conductivity depends largely on it (as seen in Table 5). The default system used for measuring conductivities may produce values some orders of magnitude lower to the ones presented in literature [22-26]. This might be due to electrode polarization. However, the series-parallel model presents a feasible fit to the shape of the observed curve. Overall, the dependence of electrical conductivity on the density of a clay plug is reflected by the model.

Table 5 Estimated parameters and computed of the total electric conductivity based on a model for series-parallel transport

\begin{tabular}{|c|c|c|c|c|c|c|c|c|}
\hline \multirow[t]{2}{*}{ Density $\left(\mathrm{g} / \mathrm{cm}^{3}\right)$} & \multirow[t]{2}{*}{ Porosity } & \multirow[t]{2}{*}{ Diff. $\mathrm{Cl}^{\mathrm{a}}$} & \multirow[t]{2}{*}{$\mathrm{m}_{+}=\mathrm{m}_{-}=\mathrm{m}$} & \multirow[t]{2}{*}{ Surface conductivity } & \multicolumn{2}{|c|}{ Total conductivity } & \multicolumn{2}{|l|}{ Parameter } \\
\hline & & & & & Predicted & Measured & $c$ & $b$ \\
\hline 1.52 & 0.35 & $6.80 \times 10^{-11}$ & $4.07 \times 10^{-1}$ & $9.64 \times 10^{-1}$ & $9.63 \times 10^{-4}$ & $1.36 \times 10^{-3}$ & $7.72 \times 10^{-7}$ & $9.99 \times 10^{-4}$ \\
\hline 1.30 & 0.45 & $6.80 \times 10^{-11}$ & $4.07 \times 10^{-1}$ & $9.64 \times 10^{-1}$ & $9.63 \times 10^{-4}$ & $1.25 \times 10^{-3}$ & $7.72 \times 10^{-7}$ & $9.99 \times 10^{-4}$ \\
\hline 1.11 & 0.53 & $1.10 \times 10^{-10}$ & $2.52 \times 10^{-1}$ & $7.61 \times 10^{-1}$ & $7.61 \times 10^{-4}$ & $9.85 \times 10^{-4}$ & $7.72 \times 10^{-7}$ & $9.99 \times 10^{-4}$ \\
\hline 1.03 & 0.56 & $1.30 \times 10^{-10}$ & $2.13 \times 10^{-1}$ & $7.11 \times 10^{-1}$ & $7.11 \times 10^{-4}$ & $8.19 \times 10^{-4}$ & $7.72 \times 10^{-7}$ & $9.99 \times 10^{-4}$ \\
\hline 0.92 & 0.61 & $1.30 \times 10^{-10}$ & $2.13 \times 10^{-1}$ & $7.11 \times 10^{-1}$ & $7.11 \times 10^{-4}$ & $4.62 \times 10^{-4}$ & $7.72 \times 10^{-7}$ & $9.99 \times 10^{-4}$ \\
\hline 0.83 & 0.65 & $1.50 \times 10^{-10}$ & $1.85 \times 10^{-1}$ & $6.74 \times 10^{-1}$ & $6.74 \times 10^{-4}$ & $2.25 \times 10^{-4}$ & $7.72 \times 10^{-7}$ & $9.99 \times 10^{-4}$ \\
\hline 0.77 & 0.67 & $2.35 \times 10^{-10}$ & $1.18 \times 10^{-1}$ & $5.87 \times 10^{-1}$ & $5.87 \times 10^{-4}$ & $5.87 \times 10^{-5}$ & $7.72 \times 10^{-7}$ & $9.99 \times 10^{-4}$ \\
\hline 0.70 & 0.70 & $2.35 \times 10^{-10}$ & $1.18 \times 10^{-1}$ & $5.87 \times 10^{-1}$ & $5.87 \times 10^{-4}$ & $4.17 \times 10^{-5}$ & $7.72 \times 10^{-7}$ & $9.99 \times 10^{-4}$ \\
\hline 0.67 & 0.72 & $2.35 \times 10^{-10}$ & $1.18 \times 10^{-1}$ & $5.87 \times 10^{-1}$ & $5.87 \times 10^{-4}$ & $3.94 \times 10^{-5}$ & $7.72 \times 10^{-7}$ & $9.99 \times 10^{-4}$ \\
\hline 0.62 & 0.74 & $2.35 \times 10^{-10}$ & $1.18 \times 10^{-1}$ & $5.87 \times 10^{-1}$ & $5.87 \times 10^{-4}$ & $3.85 \times 10^{-5}$ & $7.72 \times 10^{-7}$ & $9.99 \times 10^{-4}$ \\
\hline 0.59 & 0.75 & $2.35 \times 10^{-10}$ & $1.18 \times 10^{-1}$ & $5.87 \times 10^{-1}$ & $5.87 \times 10^{-4}$ & $2.63 \times 10^{-5}$ & $7.72 \times 10^{-7}$ & $9.99 \times 10^{-4}$ \\
\hline
\end{tabular}

${ }^{\mathrm{a}}$ Kozaki et al. [8] 


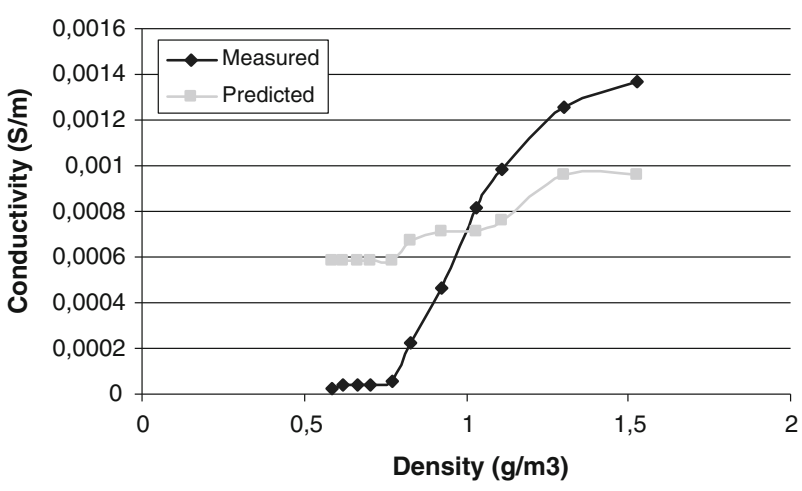

Fig. 4 Comparison between the experimentally determined electrical conductivity curve and electrical conductivity obtained with the series-parallel model

\subsection{Final considerations and future developments}

In the current study, total electrical conductivity of a compacted porous clay was established to be dependent upon density of the clay. The variation was expected to be due to surface conductivity.

For modeling total conductivities, several assumptions were made:

- Diffusivity of $\mathrm{Na}^{+}$and $\mathrm{Cl}^{-}$are equal

- Solid conductivity was considered zero

- High tortuosity.

For future developments, the zeta potential of clay such as bentonite should be adjusted according to Chassagne et al. [42]. The Smoluchowski's model is based on the assumption of spherical particles, which is not appropriate for clay platelets.

However, a compacted bentonite system hardly possesses free water in the pores, and therefore free water viscosity is a poor estimate of the viscosity of the system. For a material like bentonite with its large double layers, this could be a parameter of significant influence on the surface conductivity and should have further attention.

Overall, the combination of soil physics with surface chemistry of particles seems the appropriate way to estimate electrical conductivity of clayey porous material.

Acknowledgements The authors would like to thank the Chemistry Department, Utrecht University, in particular to Bonny Kuipers for his help in the determination of bentonite zeta potential. The research work described in this paper was funded by the Utrecht University award for KAUST Center-in-Development SOWACOR, Award No. KUK-C1-017-12.

Open Access This article is distributed under the terms of the Creative Commons Attribution Noncommercial License which permits any noncommercial use, distribution, and reproduction in any medium, provided the original author(s) and source are credited.

\section{References}

1. Coban F, Ece OI (1999) Clay Clay Miner 47(2):165

2. Sposito G (2008) The chemistry of soils, 2nd edn. Oxford University Press, New York

3. Knight WC (1898) Eng Min J 66(17):491

4. Mitchell JK (1993) Fundamentals of soil behavior. Wiley, New York

5. Müller W, Jakob I, Seeger S et al (2008) Geotext Geomembr 26(2):130

6. Alonso EE, Springman SM, Ng CWW (2008) Geotech Geol Eng 26(6):817

7. Pinto CA, Hamassaki LT, Valenzuela-Diaz FR et al (2004) J Therm Anal Calorim 77:777

8. Kozaki T, Inada K, Sato S et al (2001) J Contam Hydrol 47(24): 159

9. Bourg IC, Sposito G, Bourg ACM (2007) Environ Sci Technol 41:8118

10. Bourg IC, Sposito G, Bourg ACM (2008) Appl Geochem 23:3635

11. Mitchell JK (1991) Geotechnique 41(3):299

12. Yeung AT, Sadek SM, Mitchell JK (1992) Geotech Test J 15(3):207

13. Tegenfeldt J, Sjöblom R, Arevius A (2003) Appl Clay Sci 23(1-4):211

14. Bjerrum L, Moum J, Eide O (1967) Geotechnique 17:214

15. Acar YB, Alshawabkeh AN (1993) Environ Sci Technol 27:13

16. Saichek RE, Reddy KR (2005) Crit Rev Environ Sci Technol 35(2): 115

17. Brett CMA, Brett AMO (1993) Electrochemistry-principles, methods and applications. Oxford University Press, New York

18. Özcan A, Ömeroğlu Ç, Erdoğan Y et al (2007) J Hazard Mater 140(1-2): 173

19. Jiang Y-X, Xu H-J, Liang D-W et al (2008) C R Chim 11(12): 125

20. Telford WM, Geldart LP, Sheriff RE (1990) Applied geophysics, 2nd edn. Cambridge University Press, Cambridge

21. Velde B, Meunier A (2008) The origin of clay minerals in soils and weathered rocks. Springer, Berlin

22. Heister K, Kleingeld PJ, Loch JPG (2005) J Colloid Interf Sci 286(1):294

23. Heister K (2005) Coupled transport in clayey materials with emphasis on induced electrokinetic phenomena. Ph.D. thesis, Utrecht University, Utrecht

24. Lockhart NC, Stickland RE (1984) Powder Technol 40(1-3):215

25. Grundl T, Michalski P (1996) Water Res 30(4):811

26. Cherepy NJ, Wildenschild D (2003) Environ Sci Technol 37(13):3024

27. Das BM (2008) Advanced soil mechanics, 3rd edn. Taylor \& Francis, Washington

28. Delgado AV, González-Caballero F, Hunter RJ et al (2007) J Colloid Interf Sci 309:194

29. Bikerman JJ (1933) Z Phys Chem A163:378

30. Leroy P, Revil A (2004) J Colloid Interf Sci 270:371

31. Glaus MA, Baeyens B, Bradbury MH et al (2007) Environ Sci Technol 41:478

32. Mihoubi D, Bellagi A (2006) J Chem Thermodyn 38(9):1105

33. Chang R (2000) Physical chemistry for the chemical and biological sciences. University Science Books, Sausalito

34. Muurinen A, Olin M, Uusheimo K (1990) In: Oversby VM, Brown PW (eds) Scientific basis for nuclear waste management XIII. Materials Research Society, Pittsburgh

35. Molera M, Eriksen T (2002) Radiochim Acta 90:753

36. Schmidt E (1989) Properties of water and steam in SI-units. Springer, Berlin

37. Griffiths FJ, Joshi RC (1990) Geotechnique 40(2):303

38. Jovanovic N, Janackovic J (1991) Appl Clay Sci 6:59 
39. Shainberg I, Oster JD, Wood JD (1982) Clay Clay Miner 30(1):55

40. Clennell MB (1997) J Geol Soc Lond 122:299
41. Archie GE (1942) Petrol Technol 1:55

42. Chassagne C, Mietta F, Winterwerp JC (2009) J Colloid Interf Sci 336:352 